\title{
Cost-effectiveness of various diagnostic approaches for occupational asthma
}

\author{
Wendy A Kennedy $\mathrm{PhD}^{1}$, Frédéric Girard $\mathrm{MD}^{2}$, Simone Chaboillez $\mathrm{RT}^{2}$, André Cartier $\mathrm{MD}^{2}$, \\ Johanne Côté $M D^{3}$, Frederick Hargreave $M D^{4}$, Manon Labrecque $M D^{2}$, Jean-Luc Malo MD², \\ Susan $M$ Tarlo $\mathrm{MB} \mathrm{BS}^{5}$, Carrie A Redlich $\mathrm{MD}^{6}$, Catherine Lemière $\mathrm{MD}^{2}$
}

\begin{abstract}
WA Kennedy, F Girard, S Chaboillez, et al. Cost-effectiveness of various diagnostic approaches for occupational asthma. Can Respir J 2007;14(5):276-280.
\end{abstract}

BACKGROUND: Diagnosis of occupational asthma (OA) by specific inhalation challenge (SIC) can be costly and is not always available. The use of sputum testing to avoid this in some patients may be a more cost-effective alternative.

OBJECTIVES: To compare the cost-effectiveness of SIC with serial measurements of sputum cell counts (sputum testing) and peak expiratory flow (PEF) monitoring.

METHODS: Clinical data and testing costs for OA in 49 patients were collected during a previously published trial, modelled and compared using TreeAge Pro. Clinical outcome was the percentage of accurately diagnosed patients, using SIC as the gold standard. The PEF approach used the most accurate assessment of five experts who were blinded to SIC results. Differences in the proportion of eosinophils during periods on and off work were used for the sputum testing approach and in $\mathrm{PEF} /$ sputum for the combined approach. Unit costs were estimated from charges in Canadian hospitals. Data were analyzed by one-way and two-way analyses, and by probabilistic sensitivity analysis using a Monte Carlo simulation technique.

RESULTS: The PEF approach had an estimated accuracy of $52 \%$ and cost $\$ 365$ per patient tested. Compared with PEF monitoring, sputum testing was more accurate and cost an estimated $\$ 255$ for each additional OA patient correctly diagnosed. SIC costs per additional correct diagnosis were $\$ 11,032$ compared with sputum testing and $\$ 6,458$ compared with PEF monitoring. The combined $\mathrm{PEF} /$ sputum testing approach was not cost-effective in the base case analysis, but cannot be excluded according to probabilistic sensitivity analyses.

CONCLUSIONS: Although SIC remains the reference test to diagnose OA, when this test is not available, sputum testing is a costeffective alternative to PEF for diagnosis of OA.

Key Words: Cost-effectiveness; Diagnosis; Occupational asthma; Sputum

\section{Le coût-efficacité de diverses approches diagnostiques de l'asthme professionnel}

HISTORIQUE : Les tests de provocation par inhalation (TPI) pour diagnostiquer l'asthme professionnel (AP) peuvent être coûteux et ne sont pas toujours disponibles. Le recours au test d'expectoration pour éviter ce problème chez certains patients peut se révéler une solution plus rentable du point de vue coût-efficacité.

OBJECTIFS : Comparer le coût-efficacité du TPI à des mesures sérielles de la numération cellulaire des crachats (test d'expectoration) et de la surveillance du débit expiratoire de pointe (DEP).

MÉTHODOLOGIE : On a recueilli les données cliniques et le coût des tests pour diagnostiquer l'AP chez 49 patients pendant un essai déjà publié, modelé et comparé à l'aide de TreeAge Pro. L'issue clinique correspondait au pourcentage de patients bien diagnostiqués, le TPI constituant la norme de référence. Le DEP procurait une évaluation plus exacte, d'après cinq experts aveugles aux résultats du TPI. Les différences dans la proportion d'éosinophiles pendant les périodes de travail et d'absences du travail ont été utilisées pour le test d'expectoration, de même que pour l'association de DEP et de test d'expectoration. Les coûts de chaque unité ont été estimés d'après les facturations dans les hôpitaux du Canada. On a examiné les données au moyen d'analyses unidirectionnelles et bidirectionnelles et d'une analyse de sensibilité probabiliste par technique de simulation Monte Carlo.

RÉSULTATS : Le DEP avait une précision estimative de $52 \%$ et coûtait 365 \$ par patient testé. Par rapport à la surveillance du DEP, le test d'expectoration était plus précis et coûtait la somme estimative de 255 \$ par patient supplémentaire atteint d'AP et bien diagnostiqué. Les coûts de TPI par diagnostic correct supplémentaire étaient de 11032 \$ par rapport au test d'expectoration et de 6458 \$ par rapport à la surveillance par DEP. Dans l'analyse des cas de base, le coût-efficacité n'était pas respecté pour les tests combinés de DEP et d'expectoration, mais ces tests ne peuvent être exclus d'après l'analyse de sensibilité probabiliste.

CONCLUSIONS : Même si le TPI demeure le test de référence pour diagnostiquer l'AP, lorsque ce test n'est pas offert, le test d'expectoration est une solution de rechange au DEP, qui respecte le coût-efficacité pour diagnostiquer l'AP.

\footnotetext{
A sthma is a common health problem in Canada, with important morbidity and economic consequences. Occupational asthma (OA) has been estimated to represent approximately $15 \%$ of the burden of disease of adult asthma (1), but one Canadian study (2) suggested that it is responsible for as much as 36\% of adult-onset asthma. In Quebec, the mean cost for a patient with OA was approximately $\$ 50,000$ per patient in disability payments, as well as technical and
}

medical costs (recent data from Quebec Workers' compensation board). In the United States, OA was estimated to cost between US\$1.1 and US\$2.1 billion in 1996 (3). Long-term consequences on health and socioeconomic status are also major: a Swedish study (4) of OA claims found that four to six years after a claim for OA was made, $74 \%$ had changed their working conditions, of whom $19 \%$ had retired early and $15 \%$ were unemployed.

${ }^{1}$ Faculty of Pharmacy, Université de Montréal; ${ }^{2}$ Hôpital du Sacré-Coeur de Montréal, Montreal; ${ }^{3}$ Hôpital Laval, Sainte-Foy, Quebec; ${ }^{4}$ St Joseph's Healthcare, Hamilton; ${ }^{5}$ Toronto Western Hospital, Toronto, Ontario; ${ }^{6}$ Yale University School of Medicine, New Haven, Connecticut, USA Correspondence: Dr Catherine Lemière, Department of Chest Medicine, Sacré-Coeur Hospital, 5400 Gouin West, Montreal, Quebec H4J 1C5.

Telephone 514-338-2796, fax 514-338-3123, e-mail catherine.lemiere@umontreal.ca 
The diagnosis of OA may be difficult to establish. Despite the potential for false positive and false negative responses (5), specific inhalation challenge (SIC) is regarded as the current 'gold standard' in Quebec for diagnosing OA (6), but these tests are expensive, time consuming and require specialized equipment. SIC tests are available only in a few centres worldwide. An alternative diagnostic method is the performance of serial peak expiratory flow (PEF) monitoring during periods at work and away from work. However, serial PEFs do not have high sensitivity and specificity, and may be associated with low compliance, potential falsification of results and underestimation of changes in airway calibre (7).

Testing for changes in sputum eosinophil counts may be a cost-effective alternative of OA diagnosis. Sputum eosinophils increase during periods at work and decrease after periods away from work in subjects with OA, whereas no such changes are seen in asthmatic subjects without OA (8). Using a difference of greater than $1 \%$ increase in sputum eosinophils when at work, the addition of sputum cell counts to the monitoring of PEF increased the specificity of this test by $18 \%$, and using a difference of greater than $2 \%$, the accuracy was increased by $26.8 \%$. Similarly, sensitivity increased by $8.2 \%$ (based on the greater than 1\% increase cut-off in sputum eosinophils) or decreased by $12.3 \%$ (greater than $2 \%$ increase) (9).

Although the efficacy of the different methods for diagnosis of OA has been examined, we have found no studies assessing the comparative cost-effectiveness of the different diagnostic approaches. Therefore, using modelling techniques, the aim of the present study was to evaluate the cost-effectiveness of different approaches to assessing suspected OA in patients presenting with symptoms of asthma.

\section{METHODS}

\section{Data collection}

The data for diagnostic accuracy and costs were drawn from a previously published clinical trial (9), which compared the diagnostic accuracy of PEF and sputum testing with SIC. The methodology and results of this trial have been reported previously (9), and are briefly summarized below.

Forty-nine subjects 18 years of age or older, who were referred for possible OA, were recruited over a period of three years (2000 to 2002) in four Canadian centres specializing in OA (SacréCoeur Hospital, Montreal; Laval Hospital, Sainte-Foy; Toronto Western Hospital, Toronto; and St Joseph's Hospital, Hamilton). Most of the subjects were from the Quebec centres, and the patient sample represents roughly $50 \%$ of the initially recruited subjects. Indeed, 45 subjects were excluded because of nonproduction of sputum $(\mathrm{n}=7)$, inability to complete one of two periods at work and away from work $(n=18)$, inability to perform SIC $(n=9)$, occurrence of an exacerbation of their asthma related to other allergenic exposures or change in asthma medication during the investigation $(n=7)$, or protocol violation $(n=4)$.

Using a cross-over design with periods of two weeks at work and two weeks away from work, tests were repeated in all subjects. The clinical outcome of interest was the proportion of subjects correctly diagnosed (either true positive or true negative) according to SIC. Diagnosis for the SIC approach was conducted as previously described (10). Sputum testing relied on eosinophil counts in sputum samples induced within $48 \mathrm{~h}$ of the end of each of the two two-week periods. Sputum was induced and processed as previously described $(11,12)$.

\section{Comparison of different diagnostic strategies}

Four approaches for the assessment of suspected OA in patients presenting with symptoms of asthma were compared:

- Sputum testing: Sputum cell count analysis was performed after a two-week period at work and away from work. Patients with a difference in sputum eosinophil percentages greater than $1 \%$ between the periods at work and away from work were assumed to be positive for OA.

- PEF approach: PEF monitoring was performed during a two-week period at work and away from work. Five different experts visually blinded to SIC results analyzed the PEF graphs: the most accurate of the expert readings for OA diagnosis (compared with SIC) was used for the base case analysis (expert reader).

- SIC: SIC was considered the gold standard to identify true positives and negatives.

- Combined sputum cell count analysis and PEF monitoring: Results of the two tests were combined. When the diagnoses disagreed, the result was assumed to be inconclusive, and if missing in one test, the diagnosis was assumed to be that determined by the other test.

\section{Assessment of costs}

The costs included were those borne by the insurance program for diagnosis. Compensation and retraining costs were not included, nor were patient costs for transport and over-thecounter medications.

As a base case, the costs of diagnosis were estimated by multiplying the resource used by the prices per unit of resource. Diagnostic-testing resources, costs to administer the tests in the hospital and/or in the workplace setting, plus physician fees were included. Prices were based on per patient charges to the Quebec insurance program. Estimates and ranges for relevant unit cost variables are summarized in Table 1 .

For the estimated per patient cost of the SIC approach, the total number of testing days for SIC observed for each subject was used, attributing a specific cost to each of control days, days monitored at work and testing in the hospital. Included in the SIC costs were costs for two $\mathrm{PC}_{20}$ tests (ie, the provocative concentration of methacholine causing a 20\% decrease in forced expiratory volume in $1 \mathrm{~s}$ ). Cost parameters used in the analysis for SIC testing are found in Table 1. PEF was estimated to cost $\$ 365$ per patient and sputum testing $\$ 418$ per patient $(2 \times \$ 209$ per sputum test).

As a secondary cost analysis, charges from Yale New Haven Hospital, Connecticut, were used for most tests to estimate the American costs in US\$ (Table 1).

\section{Analyses}

A decision analysis model comparing the approaches was constructed using TreeAge Pro 2004 Suite, version 6 (TreeAge Software Inc, USA) (Figure 1). A modified per protocol approach was used: if the diagnosis was missing for a particular test, OA was considered unidentified in that subject.

Assumptions based on patient-specific trial data were the probabilities that a patient would be diagnosed as positive, negative or uncertain by any given test. Parameters for variables to populate the model (means and 95\% CIs) were generated from patient-specific clinical trial data using the statistical package SPSS version 10 (SPSS Inc, USA). 
TABLE 1

\section{Unit costs}

\begin{tabular}{|c|c|c|c|c|c|}
\hline \multirow[b]{2}{*}{ Cost variable } & \multicolumn{3}{|c|}{ Canadian costs (\$) } & \multicolumn{2}{|c|}{ American costs (US\$) } \\
\hline & Estimate & Lower & Upper & Estimate & Lower Upper \\
\hline PEF (per patient) & $365.00^{*}$ & $84.00^{\dagger}$ & $389.00^{\ddagger}$ & $20.00 \S$ & $15.00 \quad 20.00$ \\
\hline $\begin{array}{l}\mathrm{PC}_{20} \text { (methacholine) } \\
\text { testing }\end{array}$ & 107.50 & $40.00 \pi$ & $112.00^{\ddagger}$ & $530.00^{* *} 1$ & 150.00600 .00 \\
\hline Sputum testing & 209.001 & $187.00 \S \S$ & $220.00^{\ddagger}$ & $300.00 \pm$ & 80.00400 .00 \\
\hline $\begin{array}{l}\text { Per diem SIC } \\
\qquad(\text { control day })^{\S \S}\end{array}$ & 430.00 & & & $1,600.00$ & \\
\hline $\begin{array}{l}\text { Per diem SIC } \\
\quad\left(\text { exposure day) }{ }^{\S \S}\right.\end{array}$ & 530.00 & & & $1,600.00$ & \\
\hline $\begin{array}{l}\text { Per diem SIC } \\
\text { (isocyanate exposure) }\end{array}$ & 830.00 & & & 700.00 & \\
\hline Closed circuit testing§§ & $1,280.00$ & & & $1,600.00$ & \\
\hline $\begin{array}{l}\text { Average cost per day } \\
\text { of factory testing }\end{array}$ & 611.00 & & & $1,600.00$ กा & \\
\hline
\end{tabular}

*The total annual charges for peak expiratory flow (PEF) tests divided by the number of occupational asthma patients tested; the cost of 28 days of four measures of PEF per day; ${ }^{\ddagger 2002 / 2003}$ unit cost; §Cost of PEF meter only; TOne centre did not charge for these tests until 2002; **Includes \$329 hospital charge and $\$ 200$ physician interpretation fee; ${ }^{+t}$ Time and motion test costs ( $3 \mathrm{~h}$ of technician time plus costs of supplies to prepare and read standard induction sample), plus $20 \%$ overhead, plus $\$ 40$ physician interpretation fee; $¥ \neq$ Cost for two sputum tests; $\$$ Includes $\$ 115$ fee for physician supervision; IIINot performed in centres in the United States, assumed in-hospital daily cost. $P C_{20}$ Provocative concentration of methacholine causing a $20 \%$ decrease in forced expiratory volume in $1 \mathrm{~s}$; SIC Specific inhalation challenge

Cost per patient tested (in Canadian and US dollars), effect (the proportion of tested patients with a correct diagnosis), incremental cost (the difference in cost per tested patient between two approaches), incremental effect (the difference in effect between two approaches) and incremental cost-effectiveness ratio (ICER) were calculated (13). When comparing two strategies, the ICER is the ratio of the incremental cost over the incremental effect (14), and in the present study, it represents the additional cost of each correctly diagnosed subject when two approaches are compared. Cost and efficacy were plotted for each strategy.

Sensitivity analyses were conducted on all clinical and cost variables by one-way analysis, varying the point estimates of the probabilities over their 95\% CIs and the cost estimates over the range. Table 2 summarizes the results of the diagnostic accuracy. As a secondary analysis, patients with a difference in sputum eosinophil percentage greater than $2 \%$ between the periods at work and away from work were assumed to be positive for OA. The robustness of the results by two-way analysis was also explored. In addition, a probabilistic sensitivity analysis was conducted using a Monte Carlo simulation technique (15), in which the point estimates of the assumptions are varied randomly according to the distributions of the patient data to generate 95\% CIs for ICERs illustrating differences between pairs of approaches.

\section{Role of the funding source}

The sponsor of the present study had no role in the study design, data collection, analysis and interpretation of the results, nor in the writing of the report.

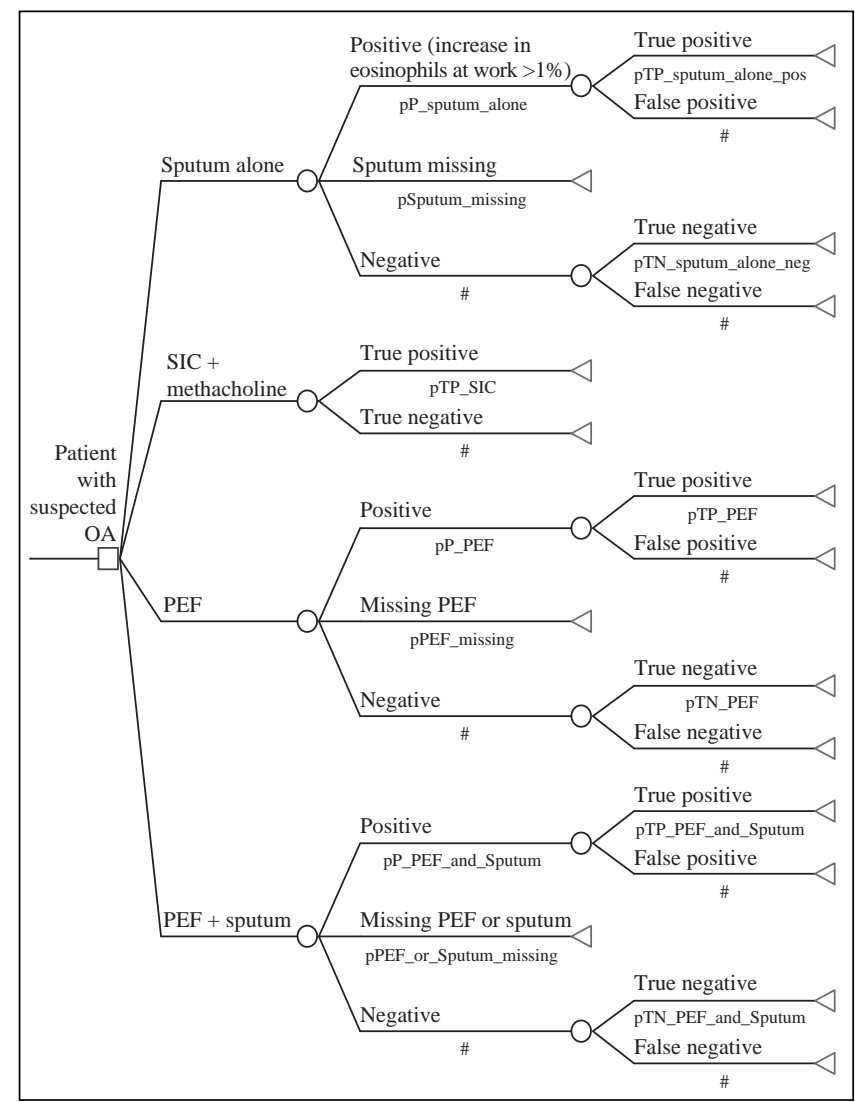

Figure 1) Decision analysis tree model comparing three approaches to diagnose occupational asthma (OA). '\#' represents the complement of the sum of the other branches from the same node; PEF Serial peak expiratory flow rate monitoring; $\mathrm{pP}$ Probability to be positive; $\mathrm{pTN}$ Probability to be truly negative; pTP Probability to be truly positive; SIC Specific inhalation challenge; Sputum Sputum-induced testing

\section{Cost-effectiveness}

\section{RESULTS}

The cost-effectiveness of the four diagnostic approaches were examined using Canadian costs (Table 3, Figure 2). The least costly and least accurate was the PEF approach. More costly and more accurate was the sputum approach (\$53 more than PEF), accurately diagnosing 20.8\% more OA patients than PEF. The SIC approach, the gold standard with an assumed $100 \%$ accuracy, was much more expensive $(\$ 3,047$ more than sputum and $\$ 3,100$ more than PEF), but correctly diagnosed $27.7 \%$ more OA patients than sputum and $48.4 \%$ more than PEF. The combined PEF/sputum approach was not cost-effective, being less effective than sputum testing alone. These results are reflected in the ICER. Specifically, compared with PEF, sputum testing cost an estimated $\$ 255$ for each additional OA patient correctly diagnosed, and SIC cost $\$ 6,458$. Compared with sputum testing, SIC cost an additional $\$ 11,013$.

Using American cost estimates, the sputum testing approach cost an estimated US $\$ 580$ per patient more than the PEF approach; the SIC approach cost an estimated US\$6,619 more per patient than PEF, and US\$6,039 more than sputum. Sputum testing cost an additional US $\$ 2,795$ more than PEF for each additional correctly diagnosed OA patient, and SIC an additional US\$21,825 more than sputum. 
TABLE 2

Parameters of diagnostic accuracy and cost for specific branches of approaches to diagnose occupational asthma (OA)

\begin{tabular}{|c|c|c|c|c|c|}
\hline \multirow[b]{2}{*}{ Clinical variables } & \multirow[b]{2}{*}{$\mathbf{n}$} & \multirow[b]{2}{*}{$\%$} & \multirow[b]{2}{*}{$95 \% \mathrm{Cl}$} & \multicolumn{2}{|c|}{ Beta distance } \\
\hline & & & & $\alpha$ & $\beta$ \\
\hline $\begin{array}{l}\text { Probability to be TP } \\
\text { according to SIC }\end{array}$ & 49 & 0.47 & $0.33-0.61$ & 22.53 & 25.47 \\
\hline $\begin{array}{l}\text { Probability to be positive } \\
\text { from PEF readings }\end{array}$ & 49 & 0.47 & $0.33-0.61$ & 22.53 & 25.47 \\
\hline $\begin{array}{l}\text { Probability to be TP } \\
\text { if positive PEF reading }\end{array}$ & 23 & 0.61 & $0.41-0.81$ & 13.39 & 8.61 \\
\hline $\begin{array}{l}\text { Probability to be TN } \\
\text { if negative PEF reading }\end{array}$ & 14 & 0.79 & $0.57-1.00$ & 10.21 & 2.79 \\
\hline PEF missing or uncertain* & 49 & 0.24 & $0.12-0.37$ & & \\
\hline Sputum >1\% & 49 & 0.43 & $0.29-0.57$ & 20.57 & 27.43 \\
\hline $\begin{array}{l}\text { Probability to be TP } \\
\text { if sputum }>1 \%\end{array}$ & 15 & 0.71 & $0.52-0.91$ & 14.29 & 5.71 \\
\hline $\begin{array}{l}\text { Probability to be TN } \\
\text { if sputum } \leq 1 \%\end{array}$ & 25 & 0.76 & $0.59-0.93$ & 18.24 & 5.76 \\
\hline Sputum missing or uncertain* & 49 & 0.02 & $-0.02-0.06$ & & \\
\hline
\end{tabular}

\begin{tabular}{lrcccc} 
& & & & \multicolumn{3}{c}{ Gamma distance } \\
\cline { 6 - 7 } Cost of SIC testing & $\mathbf{n}$ & Mean & $\mathbf{9 5 \%}$ Cl & $\alpha$ & $\boldsymbol{\alpha}$ \\
\hline Patients positive for OA (\$) & 23 & 3,216 & $2,462-3,970$ & 3.40 & 945.75 \\
Patients negative for OA (\$) & 26 & 3,279 & $2,556-4,001$ & 3.36 & 978.07 \\
Patients positive for OA (US\$) & 23 & 6,600 & $5,094-8,105$ & 3.59 & 1835.96 \\
Patients negative for OA (US\$) & 26 & 6,496 & $5,468-7,524$ & 6.52 & 997.08 \\
\hline
\end{tabular}

*Variables were entered as point estimates in the Monte Carlo simulation. PEF Serial peak expiratory flow rate monitoring; SIC Specific inhalation challenge; Sputum Sputum-induced testing; TN True negative; TP True positive

TABLE 3

Cost, effect, cost-effectiveness and incremental costeffectiveness ratio (ICER) of three approaches to diagnose occupational asthma

\begin{tabular}{lcccc}
\hline Approach & $\begin{array}{c}\text { Cost } \\
\mathbf{( \$ )}\end{array}$ & Effect & $\begin{array}{c}\text { Cost-effectiveness } \\
\mathbf{( \$ )}\end{array}$ & $\begin{array}{c}\text { ICER } \\
\mathbf{( \$ )}\end{array}$ \\
\hline PEF & 365.00 & 0.52 & 708.00 & \\
Sputum & 418.00 & 0.72 & 578.00 & 255.00 \\
PEF/sputum & 783.00 & 0.57 & $1,363.00$ & Dominated $^{*}$ \\
SIC & $3,465.00$ & 1.00 & $3,465.00$ & $11,013.00$
\end{tabular}

${ }^{*}$ Costs more than an approach of greater or similar efficacy. PEF Serial peak expiratory flow rate monitoring; SIC Specific inhalation challenge; Sputum Sputum-induced testing

The robustness of the results was confirmed by one-way and two-way sensitivity analyses of probability and cost variables in the base case analysis (using Canadian costs). Varying the cutoff point of the difference in eosinophil levels during the at-work and off-work periods from $1 \%$ (base case) to $2 \%$ (alternative efficacy scenario) did not change the conclusions, because the diagnostic accuracy of sputum testing and the combined sputum/PEF testing are decreased for the $2 \%$ cut-off point.

The robustness of the results using probability sensitivity analysis is shown in Table 4. The ICERs are large due to the relatively wide distributions for the estimated accuracy of the testing approaches, and neither of the ICERs comparing the combined sputum/PEF approaches to the sputum and the PEF

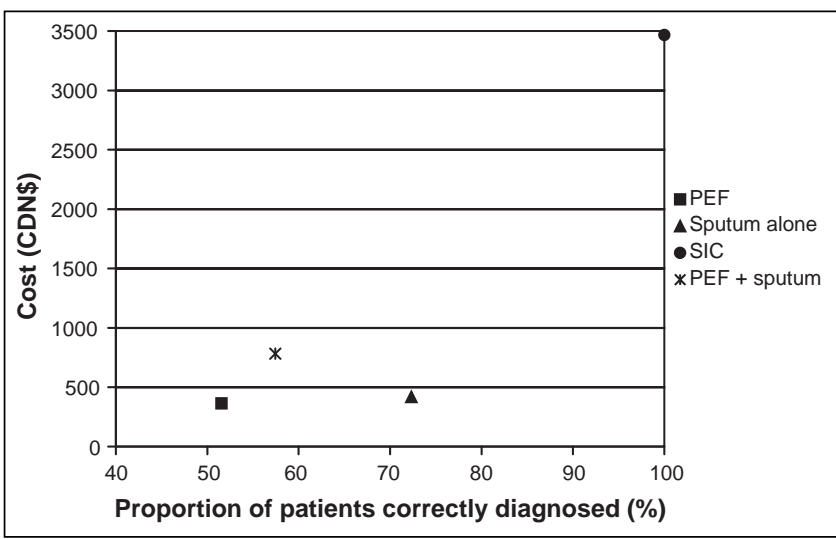

Figure 2) Cost and efficacy of three approaches to diagnose occupational asthma. PEF Serial peak expiratory flow rate monitoring; SIC Specific inhalation challenge; Sputum Sputum-induced testing

\section{TABLE 4}

Incremental cost-effectiveness of different pairs of approaches resulting from the Monte Carlo analysis

\begin{tabular}{lrrrr}
\hline Approaches compared & $\begin{array}{r}\text { Mean } \\
\mathbf{( \$ )}\end{array}$ & $\begin{array}{c}\text { Median } \\
\mathbf{( \$ )}\end{array}$ & $\begin{array}{c}\mathbf{2 . 5 \%} \\
\mathbf{( \$ )}\end{array}$ & $\begin{array}{c}\mathbf{9 7 . 5 \%} \\
\mathbf{( \$ )}\end{array}$ \\
\hline Sputum:PEF & 342.00 & 248.00 & 133.00 & $1,105.00$ \\
SIC:sputum & $11,793.00$ & $10,704.00$ & $3,788.00$ & $25,714.00$ \\
SIC:PEF & $6,504.00$ & $6,073.00$ & $2,313.00$ & $13,043.00$ \\
Sputum/PEF:PEF & $(1,805.00)$ & $3,881.00$ & $(59,053.00)$ & $66,871.00$ \\
SIC:sputum/PEF & $6,429.00$ & $5,945.00$ & $(374.00)$ & $13,842.00$ \\
Sputum/PEF:sputum & $1,723.00$ & $(2,286.00)$ & $(18,433.00)$ & $11,155.00$
\end{tabular}

Values within parentheses are negative. PEF Serial peak expiratory flow rate monitoring; SIC Specific inhalation challenge; Sputum Sputum-induced testing

approaches are statistically significant. Therefore, even if the approach combining sputum testing with PEF is not among the approaches found to be cost-effective in the base case analysis, the probabilistic sensitivity analysis shows this conclusion to fail the test of statistical significance.

\section{DISCUSSION}

The present study showed that sputum testing is a cost-effective alternative for PEF given its greater accuracy and reasonable cost. Because the efficacy outcome of interest in this evaluation was the accurate identification of patients with $\mathrm{OA}$ as determined by SIC, when PEF and sputum testing were combined, the accuracy was reduced because of the relatively high proportion of uncertain and missing values in the PEF group.

This was not an exhaustive study of the cost-effectiveness of all possible approaches to diagnose OA. We did not include immunological testing, because many subjects would not have been able to be tested using this method. Methacholine challenge alone proved less accurate than PEF in preliminary analyses, and combining PEF and methacholine challenge was less accurate than PEF alone, mainly because there was a large proportion of uncertain data resulting from disagreement between the two test results.

The selection of subjects in the present analysis may limit the ability to generalize the results of the study. Individuals wishing to claim insurance compensation in Quebec based on a diagnosis of $\mathrm{OA}$ are required to undergo SIC testing, and 
only subjects agreeing to the additional investigations of PEF and sputum testing qualified for the study. A high proportion of Ontario patients with suspected OA do not undergo SIC, and approximately $50 \%$ of initially recruited Quebec subjects failed to complete the protocol, mainly because they did not want to complete the PEF and sputum testing.

The enrolment of subjects taking inhaled corticosteroids and long-acting beta $_{2}$-agonists may have minimized the changes observed in sputum and PEF monitoring between periods at work and away from work. However, we believe that the subjects enrolled in the present study are an accurate representation of the patients seen in clinical practice. Indeed, the majority of subjects who are taking these medications cannot be weaned without impairing their asthma control.

Accuracy of the PEF and sputum tests is a function of the use of SIC as the gold standard. SIC results could have been falsely negative (5), but even if some of the subjects were incorrectly diagnosed, the results are still robust to a large variation in the estimates of clinical variables.

Charges were used instead of costs measured by time and motion study. We did, however, investigate the estimated cost of sputum testing by recording the detailed costs and time over a period of one month for these tests, and found the models to reasonably approximate the charge. Extensive sensitivity analyses using wide ranges for cost parameters also compensate for this limitation. Additionally, because the point of view of this analysis was the third-party insurance payer of the tests, the charges are the costs actually paid by the third party.

The conclusions of the present study are similar whether American or Quebec costs are used. The main differences reflect the differences in the cost structures of the approaches in the two jurisdictions. For example, the larger incremental cost of sputum compared with PEF testing was a function of the comparatively lower cost of PEF in the United States, in which only the cost of the meter is included. The higher incremental cost of SIC compared with both PEF and sputum was associated with the higher cost of testing in hospital centres in the United States, reflecting the generally higher hospital costs in the United States compared with Canada $(16,17)$.

We did not include other costs borne by the patients or by the insurance payer such as hotel and travel incurred for diagnostic testing. However, these costs would likely have not affected the order of the conclusions, because these costs were lowest in the case of PEF testing and highest when the subject had to attend the hospital centre for testing by SIC. We used Quebec costs for this analysis, and not all costs were uniform from province to province.

We also did not explore the impact of incorrect diagnosis of OA from a societal point of view, because it was beyond the scope of the study. However, even using the conservative $\$ 50,000$ per Quebec patient, an estimated cost for testing, retraining and compensation, the cost to society for accurate testing was comparatively low. Accurate diagnosis avoids unnecessarily keeping patients with $\mathrm{OA}$ in a work environment in which their disease may be aggravated or their quality of life and productivity reduced, and also avoids unnecessary retraining of individuals without $\mathrm{OA}$, with the associated personal and financial upheaval.

SICs are only available in a few settings worldwide. For example, in Ontario, only $18 \%$ of the workers compensated for OA between 1984 and 1988 underwent a SIC (18). In the settings where PEF is the only currently available diagnostic method, change to sputum testing should certainly be considered.

\section{CONCLUSION}

Although SIC remains the reference test to diagnose OA, when this test is not available, sputum testing to diagnose $\mathrm{OA}$ is a more cost-effective alternative to the tests currently available. Indeed, compared with PEF, sputum testing correctly diagnoses more patients with $\mathrm{OA}$, although it is somewhat more costly. Additional studies with larger sample sizes are needed to evaluate the cost-effectiveness of combined sputum/PEF testing compared with the approaches studied.

FUNDING: This study was supported by the Canadian Institutes of Health Research MOP-42544, and Dr Catherine Lemière holds a scholarship from the CIHR.

\section{REFERENCES}

1. Balmes J, Becklake M, Blanc P, et al. American Thoracic Society Statement: Occupational contribution to the burden of airway disease. Am J Respir Crit Care Med 2003;167:787-97.

2. Johnson AR, Dimich-Ward HD, Manfreda J, et al. Occupational asthma in adults in six Canadian communities. Am J Respir Crit Care Med 2000;162:2058-62.

3. Leigh JP, Romano PS, Schenker MB, Kreiss K. Costs of occupational COPD and asthma. Chest 2002;121:264-72.

4. Anderson EBE, Toren K. Consequences of reported occupational asthma. Eur Respir J 2001;18(Suppl 33):509s. (Abst)

5. Tarlo SM. Laboratory challenge testing for occupational asthma. J Allergy Clin Immunol 2003;111:692-4.

6. Tarlo SM, Boulet LP, Cartier A, et al. Canadian Thoracic Society guidelines for occupational asthma. Can Respir J 1998;5:289-300.

7. Moscato G, Godnic-Cvar J, Maestrelli P. Statement on selfmonitoring of peak expiratory flows in the investigation of occupational asthma. Subcommittee on Occupational Allergy of European Academy of Allergy and Clinical Immunology. J Allergy Clin Immunol 1995;96:295-301.

8. Lemière C, Pizzichini MM, Balkissoon R, et al. Diagnosing occupational asthma: Use of induced sputum. Eur Respir J 1999;13:482-8.

9. Girard, F, Chaboillez S, Cartier A, et al. An effective strategy for diagnosing occupational asthma: Use of induced sputum. Am J Respir Crit Care Med 2004;170:845-50.

10. Cartier A. Definition and diagnosis of occupational asthma. Eur Respir J 1994;7:153-60.

11. Pin I, Gibson PG, Kolendowicz R, et al. Use of induced sputum cell counts to investigate airway inflammation in asthma. Thorax 1992;47:25-9.

12. Pizzichini E, Pizzichini MM, Efthimiadis A, et al. Indices of airway inflammation in induced sputum: Reproducibility and validity of cell and fluid-phase measurements. Am J Respir Crit Care Med 1996;154:308-17.

13. van Hout BA, Al MJ, Gordon GS, Rutten FF. Costs, effects and C/E-ratios alongside a clinical trial. Health Econ 1994;3:309-19.

14. International Society for Pharmacoeconomics and Outcomes Research. Health Care Cost, Quality and Outcomes: ISPOR Book of Terms. Lawrenceville: International Society for Pharmacoeconomics and Outcomes Research, 2003.

15. Briggs AH, Mooney CZ, Wonderling DE. Constructing confidence intervals for cost-effectiveness ratios: An evaluation of parametric and non-parametric techniques using Monte Carlo simulation. Stat Med 1999;18:3245-62.

16. Bell CM, Crystal M, Detsky AS, Redelmeier DA. Shopping around for hospital services: A comparison of the United States and Canada. JAMA 1998;279:1015-7.

17. Redelmeier DA, Fuchs VR. Hospital expenditures in the United States and Canada. N Engl J Med 1993;328:772-8.

18. Tarlo SM, Liss G, Corey P, Broder I. A workers' compensation claim population for occupational asthma. Comparison of subgroups. Chest 1995;107:634-41. 


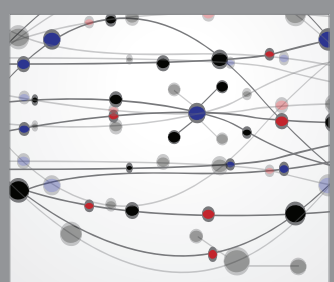

The Scientific World Journal
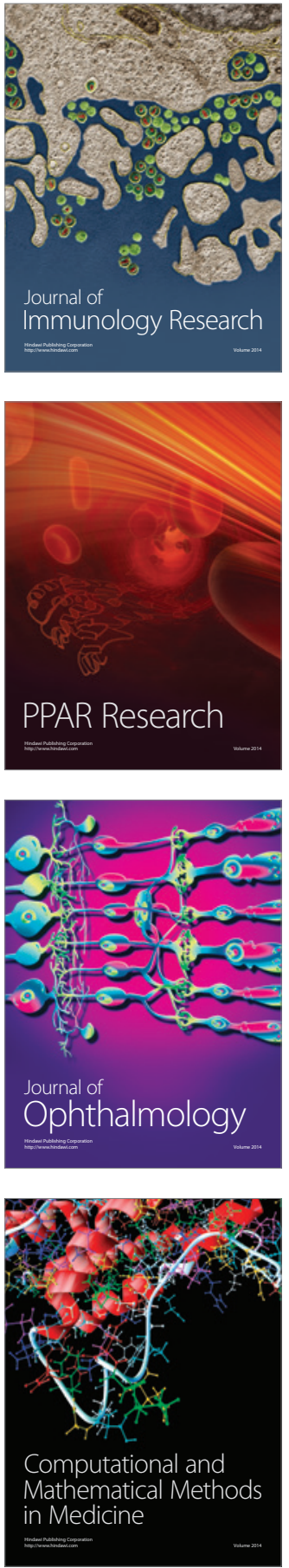

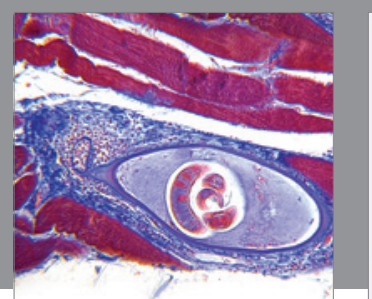

Gastroenterology Research and Practice

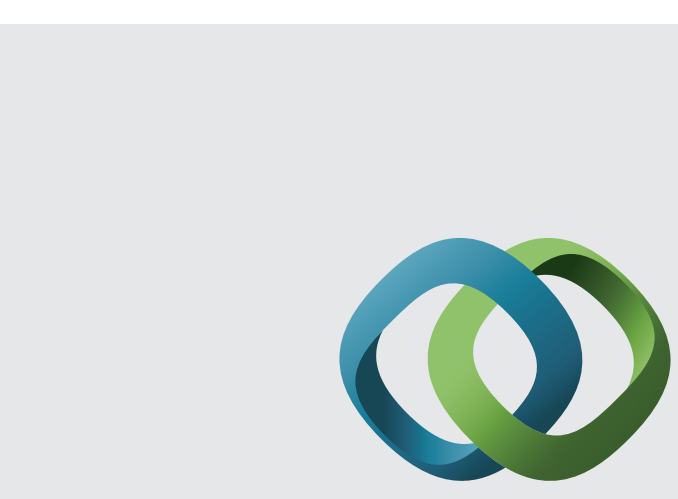

\section{Hindawi}

Submit your manuscripts at

http://www.hindawi.com
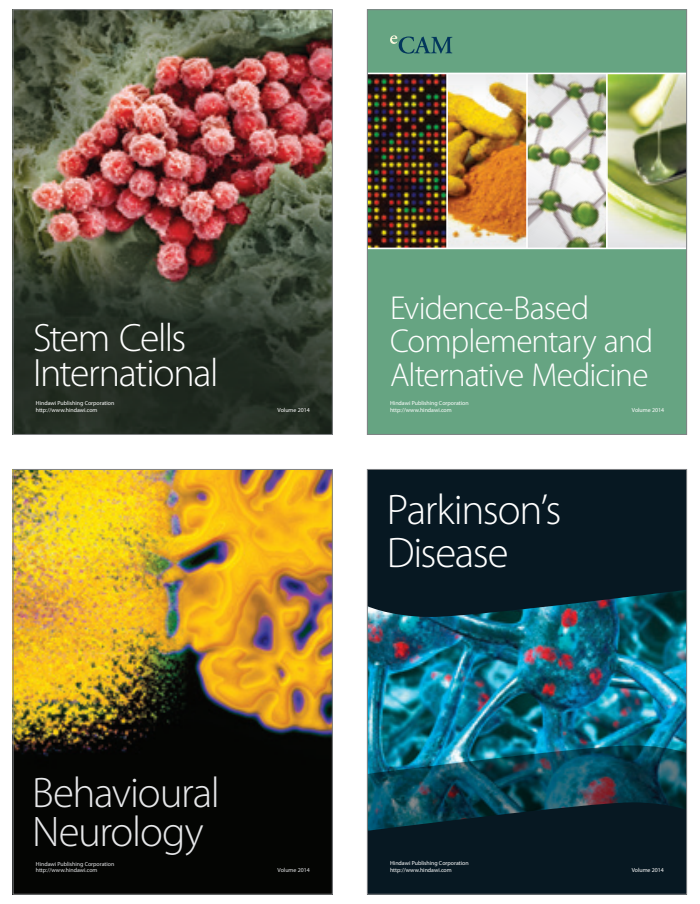
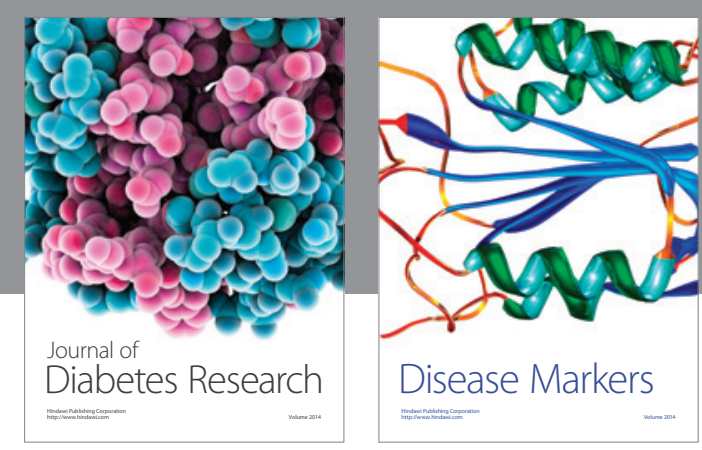

Disease Markers
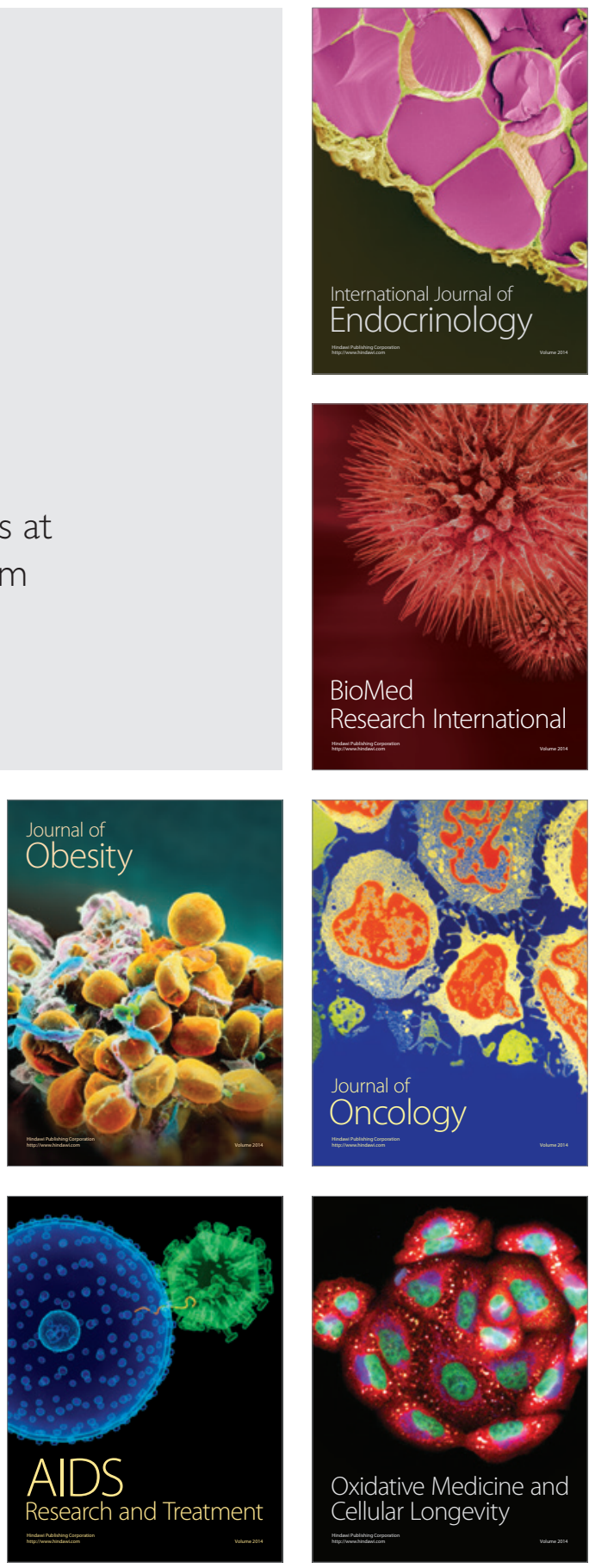